DR OMAR KUJAN (Orcid ID : 0000-0002-5951-8280)

PROFESSOR CAMILE S FARAH (Orcid ID : 0000-0002-1642-6204)

Article type : Special Issue Article

\title{
Quality of Life in Patients with Oral Leukoplakia
}

Xin Min Ang ${ }^{1 \#}$, Phil Chi Khang $\mathrm{Au}^{1 \#}$, Kevin Kwok ${ }^{1 \#}$, Ka Yeon Park ${ }^{1 \#}$, Omar Kujan ${ }^{1}$, Agnieszka M. Frydrych ${ }^{1 *}$, and Camile S. Farah ${ }^{1,2}$

${ }^{1}$ UWA Dental School, University of Western Australia, Nedlands, WA 6009, Australia

${ }^{2}$ Australian Centre for Oral Oncology Research \& Education, Nedlands, WA 6009, Australia \#These authors contributed equally to this work

*Corresponding author:

Agnieszka M. Frydrych

UWA Dental School

The University of Western Australia

17 Monash Avenue, Nedlands WA 6009, Australia

Phone: +61 864577670

Email: agnieszka.frydrych@uwa.edu.au

Camile S Farah: ORCID: 0000-0002-1642-6204

This article has been accepted for publication and undergone full peer review but has not been through the copyediting, typesetting, pagination and proofreading process, which may lead to differences between this version and the Version of Record. Please cite this article as doi: $10.1111 /$ jop. 12897

This article is protected by copyright. All rights reserved. 


\begin{abstract}
Background: Oral leukoplakia (OL) is the most common oral potentially malignant disorder, yet despite its chronic and potentially disabling nature, the literature concerning impacts of OL on quality of life (QoL) is limited. This study aimed to evaluate QoL in subjects with OL compared to controls using QoL questionnaires.
\end{abstract}

Methods: Fifty individuals with OL and 50 controls matched for age, gender, smoking and alcohol use were administered the Short Generic Health Questionnaire (SF-12) and the discipline-specific Oral Potentially Malignant Disorder Questionnaire (OPMDQ). Responses were compared between the two groups.

Results: Subjects with OL reported poorer QoL scores compared to controls in two domains "Role limitations due to physical problems" and "Pain" of the SF-12 questionnaire, and in two domains "Difficulty with diagnosis" and "Effect of treatment on daily life" and in the overall scores of the OPMDQ. Females reported poorer QoL in the overall OPMD QoL score and in the domains of "Physical and function limitation" and "Psychological and social wellbeing", while older individuals in the domains of "Physical and function limitation" and "Effect of treatment on daily life". Non-alcohol drinkers and subjects with dysplastic or nonhomogeneous OLs also reported poorer QoL scores.

Conclusions: QoL assessments provide useful insight into the impact of OL on an individual's life and opportunity to improve clinical care.

Keywords: Oral Leukoplakia, Quality of Life, Mouth Neoplasms, Case-Control Studies 


\section{Introduction}

Oral potentially malignant disorders (OPMD) represent "a morphologically altered tissue in which cancer is more likely to occur than in its apparently normal counterpart"1 . These lesions and conditions include oral leukoplakia (OL), erythroplakia, oral lichen planus (OLP), discoid lupus erythematosus, chronic graft-versus-host disease, palatal lesions in reverse smokers, actinic cheilitis and oral submucous fibrosis $(\mathrm{OSF})^{2}$. Evidence suggests that a diagnosis of OPMD may be associated with increased levels of anxiety ${ }^{3-5}$ resulting from prolonged state of uncertainty, a feeling of loss of control, fear of treatment complications and the chronic state of oral discomfort ${ }^{4,5}$. Although assessments of quality of life (QoL) are gaining increasing importance in the evaluation of disease and intervention outcomes, and are becoming an important indicator of service need ${ }^{6}$; thus far, the QoL in individuals with OPMDs has received little attention in the literature ${ }^{6-10}$.

Oral leukoplakia is a predominantly white plaque of questionable risk having excluded (other) known diseases or disorders that carry no increased risk for cancer ${ }^{11}$. With an estimated average worldwide prevalence of $2 \%^{12,13}$, it is considered to represent the most common OPMD, with an Australian annual malignant transformation rate of $1 \%{ }^{14}$. The aetiology of OL remains to be fully elucidated and is likely to be multifactorial. Tobacco and alcohol use constitute important risk factors ${ }^{15}$. Management of OL remains a challenge in view of the difficulties associated with prediction of disease progression, stability or regression, and the consequent lack of clear evidence-based guidelines ${ }^{16}$. While it can be argued that all OLs should be surgically treated to reduce the risk of oral squamous cell carcinoma (OSCC) formation, this is not always possible and ultimately numerous disease and patient characteristics impact on the decision to initiate treatment or recommend surveillance, with either decision potentially having QoL implications.

This article is protected by copyright. All rights reserved. 
To date, only a handful of studies have assessed QoL in individuals with $\mathrm{OL}^{8,9,17}$ utilizing tools such as the Short Form-36 and the Oral Health Impact Profile-14, ${ }^{9}$ however interpretation of QoL changes specific to OL subjects is difficult, as either OL subjects are grouped together with individuals presenting with other oral mucosal pathosis ${ }^{9}$ or healthy control groups are not utilized ${ }^{8}$. In 2018, Tadakamadla et al. ${ }^{17}$ published QoL data specific to OL, OLP and OSF using a recently developed discipline-specific QoL questionnaire to evaluate QoL in individuals with OPMDs. However, as subjects with OL were used as the control group to compare OPMD QoL scores with OLP and OSF, the QoL of OL subjects remains unknown, although shown to be better than in those with OLP and OSF ${ }^{17}$.

Although limited, the emerging evidence does suggest impaired QoL in subjects with OPMDs. Thus, the overall objective of this study was to assess the QoL in individuals with OL, the most common OPMD. The specific aims were to: (1) assess the QoL in subjects with OL using the discipline-specific, 20-point OPMDQ and the Short Generic Health Questionnaire (SF-12) compared to controls matched for age, gender, smoking and alcohol use; (2) assess the effects of patient and lesion characteristics on QoL scores and (3) better understand the factors which influence QoL in individuals with OL. It is anticipated that results of this study will broaden our understanding of the QoL in individuals with OL, improving our knowledge of the impact of the disease and its treatment, ultimately leading to improved patient care.

\section{Methods}

This was a cross-sectional, case-control study approved by the Human Research Ethics Committee of the University of Western Australia (RA/4/1/9201). Participants were selected from a pool of patients attending the general dental and oral medicine clinics at the Oral 
Health Centre of Western Australia (OHCWA), UWA Dental School, University of Western Australia, between August 2017 and October 2018.

Cases included in this study were diagnosed with OL based on both clinical findings and histopathology at least 3 months prior to recruitment, and were identified using OHCWA patient electronic database. All subjects had their OL(s) fully excised and/or monitored. Subjects who underwent excision of OL(s), did so at least 3 months prior to their inclusion in the study. Cases with concurrent oral mucosal disorders other than OL and those in pain not due to OL or its treatment were excluded. Controls free of oral mucosal disease and pain were recruited from the OHCWA general dental clinics, attending for a routine dental examination. All individuals less than 18 years of age; unable to give consent and those with compromised dentition (less than 20 natural teeth or inadequate replacement) were excluded from the study.

Following the scheduled examination, either in the oral medicine clinic (for the OL cases) or the general dental clinic (for the controls), prospective subjects were approached and invited to participate in the study. The age, gender, residential post code, medical history, smoking and alcohol consumption, presence of oral mucosal disease, presence of pain and the general dental status were recorded for each participant. For the OL cases, all lesion characteristics were recorded including time since diagnosis, lesion site, size, homogeneity, symptoms, histopathology and treatment details including treatment type, number of treatment attempts and time since treatment completion. All participants were also asked to complete the OPMD and SF-12 Questionnaires.

This article is protected by copyright. All rights reserved. 


\section{Statistical analysis}

All records were de-identified and the data manually entered into Excel Microsoft (Redmond, WA USA) and verified by two independent clinicians to prevent data transfer error. The data was then transferred to SPSS (Version 22.0. IBM Corp, Armonk, NY, USA) for statistical analyses. Cases and controls were matched for gender, age category $(<45$ or $\geq 45)$ and smoking/alcohol use. Normality testing was carried out using the Kolmogorov-Smirnov and Shapiro-Wilk tests on SF-12 domain scores, OPMD QoL total and subtotal domain scores. As the SF-12 domain scores, OPMD QoL total and subtotal domain scores did not follow a normal distribution (Table S1), non-parametric analyses (Mann-Whitney U test, KruskalWallis test, Spearman's correlation test and Pearson's Chi-squared association test with odds ratio and relative risk tabulated) were carried out with statistical significance set at $\mathrm{p}<0.05$. Multivariate linear regression analysis with the generalized linear model (GLM) was performed to assess the adjusted effects of patient characteristics (age and gender) as independent continuous co-variables on OPMD QoL scores for all variables studied: age group, gender, medical condition, medication use, smoking, alcohol use, lesion site, lesion size, lesion homogeneity, lesion symptoms, treatment type, time since diagnosis, single vs multi-focal lesion, lesion and histopathology. Statistical significance was set at $\mathrm{p}<0.05$.

\section{Results}

Fifty subjects (30 male, 20 female) with OL were recruited prospectively. One hundred were selected as the control group, of these 50 were strictly matched by age, gender, smoking and alcohol use to the OL subjects and included in the study. There were no significant differences between the demographic characteristics of OL and control participants $(\mathrm{p}=0.764)$. The clinical and demographic characteristics of the cases are presented in Table 1 . The mean age of OL and control subjects was $66.42 \pm 13.48$ (mean \pm standard deviation) and 
$61.72 \pm 14.15$, respectively. The topographical distribution of the lesions was as follows: buccal mucosa (22\%), lateral surface of tongue (20\%), alveolar ridge (12\%), floor of mouth $(12 \%)$, palate $(8 \%)$, ventral surface of tongue $(8 \%)$, lip $(6 \%)$, labial mucosa $(4 \%)$, gingiva $(4 \%)$, dorsal surface of tongue $(2 \%)$ and alveolar mucosa $(2 \%)$. Thirty eight percent of the OL subjects had more than one lesion; $14 \%$ had lesions that were symptomatic; $54 \%$ had non-homogeneous lesions; and $48 \%$ had lesions larger than $200 \mathrm{~mm}^{2}$. Only $46 \%$ of OLs were dysplastic.

All the included cases and controls answered all the questions with a $100 \%$ response rate. Table 2 illustrates the comparison between OL and control subjects using the SF-12 and OPMD QoL questionnaires. The SF-12 tool identified "Pain" and "Role limitations due to physical problems" as the only parameters to demonstrate a significant difference between the cases and controls. Likewise, there were significant differences between cases and controls in the overall total of OPMD QoL scores and in the domains of "Difficulties with diagnosis" and "Effects of treatment on daily life", with the OL subjects reporting significantly higher scores, translating to a poorer QoL.

Table 3 illustrates the impact of the main variables of subjects' demographics and lesion characteristics on OPMD QoL scores. Females showed poorer QoL than males $(\mathrm{p}=0.018)$. Compared to younger participants, older subjects reported significantly poorer QoL in the domains of "Physical and functional limitation" ( $\mathrm{p}=0.029)$ and "Effect of treatment on daily life" $(p=0.029)$. Non-alcohol drinkers reported poorer QoL in the overall total score $(p=0.002)$ and in the domains of "Physical and functional limitation" $(p=0.002)$ and "Psychological and social well-being" ( $p=0.030$ ). Subjects with lesions greater than $200 \mathrm{~mm}^{2}$ reported poorer QoL in the overall total score $(\mathrm{p}=0.038)$. Individuals with non-homogeneous 
lesions reported poorer QoL in the overall total score $(\mathrm{p}=0.036)$ and the domain of "Effect of treatment on daily life" ( $\mathrm{p}=0.023)$. Subjects with dysplastic lesions also reported poorer QoL in overall total score $(\mathrm{p}=0.027)$, and in the domains of "Difficulties with diagnosis" $(\mathrm{p}=0.013)$ and "Psychological and social well-being" $(\mathrm{p}=0.010)$.

Interestingly, treatment type (excision versus surveillance); single or multiple lesions; lesion site and whether the lesion was symptomatic showed no statistical differences in any of the OPMD QoL domains or the overall total scores (Table S2).

Multivariate linear regression analyses with adjusted patient age and gender showed that smoking and alcohol use, time since diagnosis, lesion site (floor of mouth) and treatment type (excision) had a significant impact on participants' OPMD QoL scores, particularly in the domains of "Physical and functional limitations" and "Psychological and social well-being" and in the OPMDQ total score (Table 4).

Association analyses using Chi-squared showed significant associations (Table 5) between several parameters. The presence of a medical condition was significantly associated with use of medication $(p<0.001)$, older subjects $(p=0.001)$, non-smokers $(p=0.022)$, nonhomogeneous $(\mathrm{p}=0.011)$ and larger lesions $(\mathrm{p}=0.024)$. Asymptomatic $(\mathrm{p}=0.005)$ and large lesions $(\mathrm{p}=0.016)$ were more likely to be managed with surveillance. Older subjects were more likely to be non-smokers $(\mathrm{p}=0.013)$ and take medication $(\mathrm{p}=0.014)$. High risk lesion characteristics such as those that were non-homogeneous, dysplastic and large were significantly associated with each other (Table 5). Interestingly, non-smokers were associated with higher risk non-homogeneous lesions $(\mathrm{p}=0.012, \mathrm{R}=2.118)$, while alcohol users with the lower risk smaller lesions $(\mathrm{p}=0.046, \mathrm{RR}=1.733)$.

This article is protected by copyright. All rights reserved. 


\section{Discussion}

Assessments of life quality are gaining increasing importance in the evaluation of disease and intervention outcomes and are becoming an important indicator of service need. In this first study, we evaluated the QoL of individuals with OL compared to disease-free controls matched for age, gender, smoking and alcohol use, using the generic SF-12 and the discipline specific OPMD questionnaires. Statistically significant differences were observed between individuals with OL and controls, utilizing the generic SF-12 questionnaire in the domains of "Role limitations due to physical problems" and "Pain" suggesting that even a generic questionnaire has the ability to detect changes in the QoL of OL subjects. However, this is not to the same extent as the discipline-specific OPMDQ, particularly in identifying specific QoL parameters related to OL.

Compared to controls, QoL of OL subjects was impaired in the overall OPMDQ score and in domains of "Difficulty with diagnosis" and "Effects of treatment on daily life". This is consistent with numerous studies in which individuals with oral mucosal lesions, including OL, show impaired QoL using various QoL instruments ${ }^{6-10,17-19}$. Both female and older subjects, displayed poorer QoL in the OPMDQ scores than their counterparts. This is also consistent with other studies ${ }^{7,8,17,20}$. Females reported poorer QoL in the overall score as well as in domains "Physical and functional limitation" and "Psychological and social wellbeing". This result is not surprising. Interactions between gender and the determinants and consequences of chronic diseases are well known, with females generally more adversely affected $^{21}$. Females are known to suffer more anxiety and depression, are less likely to receive support from their families (leading to less positive coping), and are more prone to accept their condition as part of themselves, rather than to see it as a challenge to be overcome $^{21}$. 
Older adults were found to be more affected in the domains of "Physical and functional limitation" and "Effect of treatment on daily life". It should be noted however that the majority $(94 \%)$ of subjects were in the older age category and caution should be exercised with the interpretation of this finding. Older individuals may experience more difficulties coping with treatment due to their comorbidities and may have greater difficulty commuting to appointments.

Subjects with larger and non-homogeneous lesions reported poorer QoL in the overall OPMD QoL score and in the domain "Effects of treatment on daily life" respectively. Given that larger and non-homogeneous lesions are associated with increased risk of malignant transformation $^{22}$, this result may be attributed to physical and psychosocial sequelae of excisional treatment of lesions with larger sizes and/or the need for frequent recall visits for surveillance of such lesions. Life quality was more impacted in non-alcohol users relating to the domains "Physical and functional limitation", "Psychological and social well-being" and in the overall OPMD QoL score. Further research is needed to clarify why this difference exists as alcohol consumption is often cited as a critical risk factor for OPMDs ${ }^{15}$. Perhaps a subset of subjects diagnosed with OL could previously enjoy their alcohol consumption but ceased this habit due to the presence of this oral lesion.

The presence of dysplasia appears to impact on the OL subjects' QoL in the domains of "Difficulties with diagnosis", "Psychological and social well-being" and the overall OPMD QoL score. As the presence of dysplasia is another well-known risk factor for malignant transformation of $\mathrm{OL}^{22}$, the poorer QoL in this group may be explained by the anxiety associated with the unknown outcome of their disease, the more aggressive treatment required and the need for frequent and indefinite lesion surveillance. Absence of significant 
QoL differences in the various stages of dysplasia, may in part be explained by the small sample size of subjects presenting with severe $(n=5)$ and moderate $(n=5)$ dysplasia. Similarly, lack of significant differences in OPMD QoL scores between lesion sites and symptomatic or asymptomatic lesions may also be attributed to a small sample size in one of the categorical variables, making statistical analysis insignificant. Future studies with larger sample sizes may provide additional insights into the effect of lesion site and symptoms on QoL.

The effect of treatment type (excision versus surveillance) on OPMD QoL scores were significant only when the effects of patient characteristics (age and gender) were adjusted in the analyses. This suggests that age and gender are important variables to consider when assessing the potential impact of surgical intervention on the QoL of individuals with OL.

OL subjects were predominantly older males over 45 years of age with lesions most frequently found on the buccal mucosa, consistent with current literature ${ }^{14}$. In this study, OL subjects presented with roughly equal proportion of homogeneous and non-homogeneous lesions, and were mostly non-smokers and non-drinkers. This contrasts with results presented by Karbach et al. (2014) whereby homogeneous lesions predominated and the participants were mostly drinkers with equal proportion of smokers and non-smokers ${ }^{8}$. Our results may be explained by the differences in geographical location and cultural habits of the patient population studied. Australia is a country which imposes heavy tax on tobacco and alcohol purchases. Furthermore, excessive alcohol and smoking habits are usually frowned upon. It should also be noted that one of our inclusion criteria involved the presence of 20 natural teeth or adequate replacement, and it is well known that smoking is associated with poorer dental health ${ }^{23}$.

This article is protected by copyright. All rights reserved. 
Consistently, our correlation analysis showed an inverse relationship between age and smoking or alcohol habit, whereby a decline in those habits was observed as the age of the participants increased. An increased awareness of healthy lifestyle habits, along with a diagnosis of OL may have impacted on the tobacco and alcohol habits of the participants.

Oral leukoplakias with lower malignant potential include homogeneous lesions and lesions smaller than $200 \mathrm{~mm}^{2}$, while those with higher malignant potential are non-homogeneous, dysplastic and larger than $200 \mathrm{~mm}^{2} 24$. This is consistent with our findings where significant associations were observed in lesion characteristics that present with low or high malignant potential. A significant association between large lesions and the presence of a medical condition was also found. Although little is known about comorbidity in OL subjects, the literature does suggest that associations exist between some medical conditions and OL, particularly diabetes ${ }^{25}$.

Interestingly, our association analyses showed a strong link between lesions of low malignant potential, namely smaller and homogeneous lesions, and subjects with smoking or alcohol habits. While smoking and alcohol consumption are established etiological factors for the formation of OPMDs, the progression of these OPMDs may be related to either the practice of or continued practice of these habits. Although alcohol consumption and its relationship with low malignant potential lesions is a new finding, currently there is a compelling body of evidence to support the notion that OPMD patients who are non-smokers are at increased risk for lesion progression to cancer ${ }^{24,26-33}$. While the mechanism remains to be fully elucidated, it is possible that non-smokers and/or non-drinkers who develop OPMDs are already at an increased genetic predisposition which may play a role in a proportion of these cases. Further research is required to understand medical comorbidities, smoking and alcohol habits and 
their relationship with malignant transformation potential. Such research may identify useful predictors of cancer progression and facilitate early intervention.

We present the first Australian-based data on the QoL of individuals with OL. We present compelling evidence that the QoL of OL subjects is impaired compared to controls, particularly in females and older individuals. In light of the lack of clinical guidelines for the management of OL, we hope that this study can provide useful insight into the impact of OL on an individual's QoL and contribute to the development of such guidelines. Where a decision to treat or monitor cannot be easily established, the clinical decision may be facilitated by taking into consideration the adverse QoL implications on female gender and the older patient.

\section{Acknowledgements}

We would like to thank all our patients for their willing participation, the University of Western Australia Dental School for funding, the Oral Medicine Registrars for their assistance and the Oral Oncology Research Program for advice and support during this project.

\section{Conflict of Interest}

All authors declare that they do not have any conflict of interests.

\section{References}

1. Amagasa T, Yamashiro M, Uzawa N. Oral premalignant lesions: from a clinical perspective. Int J Clin Oncol. 2011;16(1):5-14.

2. Mortazavi $H$, Baharvand M, Mehdipour M. Oral potentially malignant disorders: an overview of more than 20 entities. J Dent Res Dent Clin Dent Prospects. 2014;8(1):6-14.

3. Gavic L, Cigic L, Biocina Lukenda D, et al. The role of anxiety, depression, and psychological stress on the clinical status of recurrent aphthous stomatitis and oral lichen planus. Journal of Oral Pathology \& Medicine. 2014;43(6):410-417.

This article is protected by copyright. All rights reserved. 
4. Lin HY, Chen SC, Peng HL, et al. Unmet information needs and clinical characteristics in patients with precancerous oral lesions. European Journal of Cancer Care. 2015;24(6):911919.

5. Flaitz CM, Carlin N. Living in limbo: Ethics and experience in a conversation about persistent oral lesions. Texas dental journal. 2013;130(8):692-701.

6. Tadakamadla J, Kumar S, Johnson NW. Quality of life in patients with oral potentially malignant disorders: a systematic review. Oral Surgery Oral Medicine Oral Pathology Oral Radiology. 2015;119(6):644-655.

7. Tabolli S, Di Pietro C, Sampogna F, Abeni D. Quality of life and psychological problems in patients with oral mucosal diseases. Value in Health. 2008;11(3):A296-A297.

8. Karbach J, Al-Nawas B, Moergel M, Daublander M. Oral Health-Related Quality of Life of Patients With Oral Lichen Planus, Oral Leukoplakia, or Oral Squamous Cell Carcinoma. Journal of Oral and Maxillofacial Surgery. 2014;72(8):1517-1522.

9. Liu $L$, Xiao W, He QB, Jiang WW. Generic and oral quality of life is affected by oral mucosal diseases. BMC Oral Health. 2012;12:2.

10. Llewellyn $C D$, Warnakulasuriya $S$. The impact of stomatological disease on oral healthrelated quality of life. Eur J Oral Sci. 2003;111(4):297-304.

11. Van Der Waal I. Oral leukoplakia, the ongoing discussion on definition and terminology. Med Oral Patol Oral Cir Bucal. 2015;20(6):e685-e692.

12. Bokor-Bratić M. Prevalence of Oral Leukoplakia. Med Pregl. 2003;56(11-12):552-555.

13. Petti S. Pooled estimate of world leukoplakia prevalence: a systematic review. Oral Oncol 2003;39(8):770-780.

14. Dost F, Le Cao K, Ford PJ, Ades C, Farah CS. Malignant transformation of oral epithelial dysplasia: a real-world evaluation of histopathologic grading. Oral Surg Oral Med Oral Pathol Oral Radiol. 2014;117(3):343-352.

15. Bánóczy J, Gintner Z, Dombi C. Tobacco use and oral leukoplakia. J Dent Educ. 2001;65(4):322-327.

16. Lodi G, Porter S. Management of potentially malignant disorders: evidence and critique. J Oral Pathol Med. 2007;37(2):63-69.

17. Tadakamadla J, Kumar S, Lalloo R, Babu DBG, Johnson NW. Impact of oral potentially malignant disorders on quality of life. Journal of Oral Pathology \& Medicine. 2018;47(1):6065.

18. Lopez-Jornet P, Camacho-Alonso F. Quality of life in patients with oral lichen planus. J Eval Clin Pract. 2010;16(1):111-113.

19. Riordain RN, McCreary C. The use of quality of life measures in oral medicine: a review of the literature. Oral Diseases. 2010;16(5):419-430.

20. Rajan B, Ahmed J, Shenoy N, Denny C, Ongole R, Binnal A. Assessment of quality of life in patients with chronic oral mucosal diseases: a questionnaire-based study. Perm J. 2014;18(1):e123-127.

21. Vlassoff $C$. Gender differences in determinants and consequences of health and illness. $J$ Health Popul Nutr. 2007;25(1):47-61.

22. Warnakulasuriya $S$, Ariyawardana A. Malignant transformation of oral leukoplakia: a systematic review of observational studies. J Oral Pathol Med. 2016;45(3):155-166.

23. Warnakulasuriya $S$, Dietrich $\mathrm{T}$, Bornstein MM, et al. Oral health risks of tobacco use and effects of cessation. Int Dent J. 2010;60(1):7-30.

24. Speight PM, Khurram SA, Kujan O. Oral potentially malignant disorders: risk of progression to malignancy. Oral Surg Oral Med Oral Pathol Oral Radiol. 2018;125(6):612-627.

25. Gong Y, Wei B, Yu L, Pan W. Type 2 diabetes mellitus and risk of oral cancer and precancerous lesions: a meta-analysis of observational studies. Oral Oncol. 2015;51(4):332340.

26. Banoczy J. Follow-up studies in oral leukoplakia. J Maxillofac Surg. 1977;5(1):69-75.

This article is protected by copyright. All rights reserved. 
27. Einhorn J, Wersall J. Incidence of oral carcinoma in patients with leukoplakia of the oral mucosa. Cancer. 1967;20(12):2189-2193.

28. Ho MW, Risk JM, Woolgar JA, et al. The clinical determinants of malignant transformation in oral epithelial dysplasia. Oral Oncol. 2012;48(10):969-976.

29. Hogewind WF, van der Kwast WA, van der Waal I. Oral leukoplakia, with emphasis on malignant transformation. A follow-up study of 46 patients. J Craniomaxillofac Surg. 1989;17(3):128-133.

30. Kumar S, Debnath N, Ismail MB, et al. Prevalence and Risk Factors for Oral Potentially Malignant Disorders in Indian Population. Adv Prev Med. 2015;2015:208519.

31. Reibel J. Prognosis of oral pre-malignant lesions: significance of clinical, histopathological, and molecular biological characteristics. Crit Rev Oral Biol Med. 2003;14(1):47-62.

32. Schepman KP, van der Meij EH, Smeele LE, van der Waal I. Malignant transformation of oral leukoplakia: a follow-up study of a hospital-based population of 166 patients with oral leukoplakia from The Netherlands. Oral Oncol. 1998;34(4):270-275.

33. Silverman S, Jr., Gorsky M, Lozada F. Oral leukoplakia and malignant transformation. A follow-up study of 257 patients. Cancer. 1984;53(3):563-568.

This article is protected by copyright. All rights reserved. 
TABLE 1: Patients' demographics and clinical characteristics of oral leukoplakia lesions; number $(\%)$

\begin{tabular}{|c|c|c|c|c|c|c|}
\hline \multirow{4}{*}{ atient characteristics } & \multirow{2}{*}{$\begin{array}{l}\text { Gender } \\
\text { Age }\end{array}$} & \multicolumn{2}{|r|}{$\begin{array}{c}\text { Male } \\
30(60 \%)\end{array}$} & & \multicolumn{2}{|c|}{$\begin{array}{c}\text { Female } \\
20(40 \%)\end{array}$} \\
\hline & & \multicolumn{2}{|r|}{$\begin{array}{l}<45 \\
3(6 \%)\end{array}$} & & \multicolumn{2}{|c|}{$\begin{array}{c}\geq 45 \\
47(94 \%)\end{array}$} \\
\hline & Smoker & \multicolumn{2}{|r|}{$\begin{array}{c}\text { Yes } \\
17(34 \%)\end{array}$} & & \multicolumn{2}{|c|}{ No } \\
\hline & Alcohol user & \multicolumn{2}{|r|}{ Yes } & & \multicolumn{2}{|c|}{$26(52 \%)$} \\
\hline \multirow{7}{*}{$\begin{array}{c}\text { Oral leukoplakia } \\
\text { lesion } \\
\text { characteristics/manag } \\
\text { ement }\end{array}$} & $\begin{array}{l}\text { Lesion size > } \\
200 \mathrm{~mm}\end{array}$ & \multicolumn{2}{|r|}{$\begin{array}{c}\text { Yes } \\
26(42 \%)\end{array}$} & & \multicolumn{2}{|c|}{ No } \\
\hline & Homogeneous & \multicolumn{2}{|r|}{$23(46 \%)$} & & \multicolumn{2}{|c|}{$\begin{array}{c}\text { No } \\
27(54 \%)\end{array}$} \\
\hline & Symptomatic & \multicolumn{2}{|r|}{$\begin{array}{c}\text { Yes } \\
7(14 \%)\end{array}$} & & \multicolumn{2}{|c|}{ No } \\
\hline & Management & \multicolumn{2}{|c|}{$\begin{array}{r}\text { Monitor } \\
31(62 \%)\end{array}$} & & $\begin{array}{l}\text { Exc } \\
19\end{array}$ & $19(38 \%)$ \\
\hline & $\begin{array}{l}\text { Time since } \\
\text { diagnosis }\end{array}$ & \multicolumn{2}{|c|}{$\begin{array}{l}<6 \text { months } \\
11(22 \%)\end{array}$} & $\begin{array}{r}6-12 \mathrm{r} \\
23(\end{array}$ & $\begin{array}{l}\text { onths } \\
\%)\end{array}$ & $\begin{array}{c}>12 \text { months } \\
16(32 \%)\end{array}$ \\
\hline & $\begin{array}{l}\text { Histopathology } \\
\text { diagnosis } \\
\text { (OED - oral epithelial } \\
\text { dysplasia) }\end{array}$ & \multicolumn{2}{|c|}{$\begin{array}{c}\text { No } \\
\text { OED } \\
27(54 \%)\end{array}$} & $\begin{array}{l}\text { Mild } \\
\text { OED } \\
13 \\
(26 \%)\end{array}$ & $\begin{array}{c}\text { Moderate } \\
\text { OED } \\
5(10 \%)\end{array}$ & $\begin{array}{l}\text { Severe } \\
\text { OED } \\
5(10 \%)\end{array}$ \\
\hline & No. Lesions & $\begin{array}{c}1 \\
\text { lesion } \\
19 \\
(38 \%)\end{array}$ & $\begin{array}{c}2 \\
\text { lesions } \\
11 \\
(22 \%)\end{array}$ & $\begin{array}{c}3 \\
\text { lesions } \\
3(6 \%)\end{array}$ & $\begin{array}{c}4 \\
\text { lesions } \\
4(8 \%)\end{array}$ & $\begin{array}{c}5 \\
\text { lesions } \\
1(2 \%)\end{array}$ \\
\hline
\end{tabular}

This article is protected by copyright. All rights reserved. 
TABLE 2: Comparison between controls and OL patients using SF-12 and OPMD QoL questionnaire (Mann-Whitney U test)

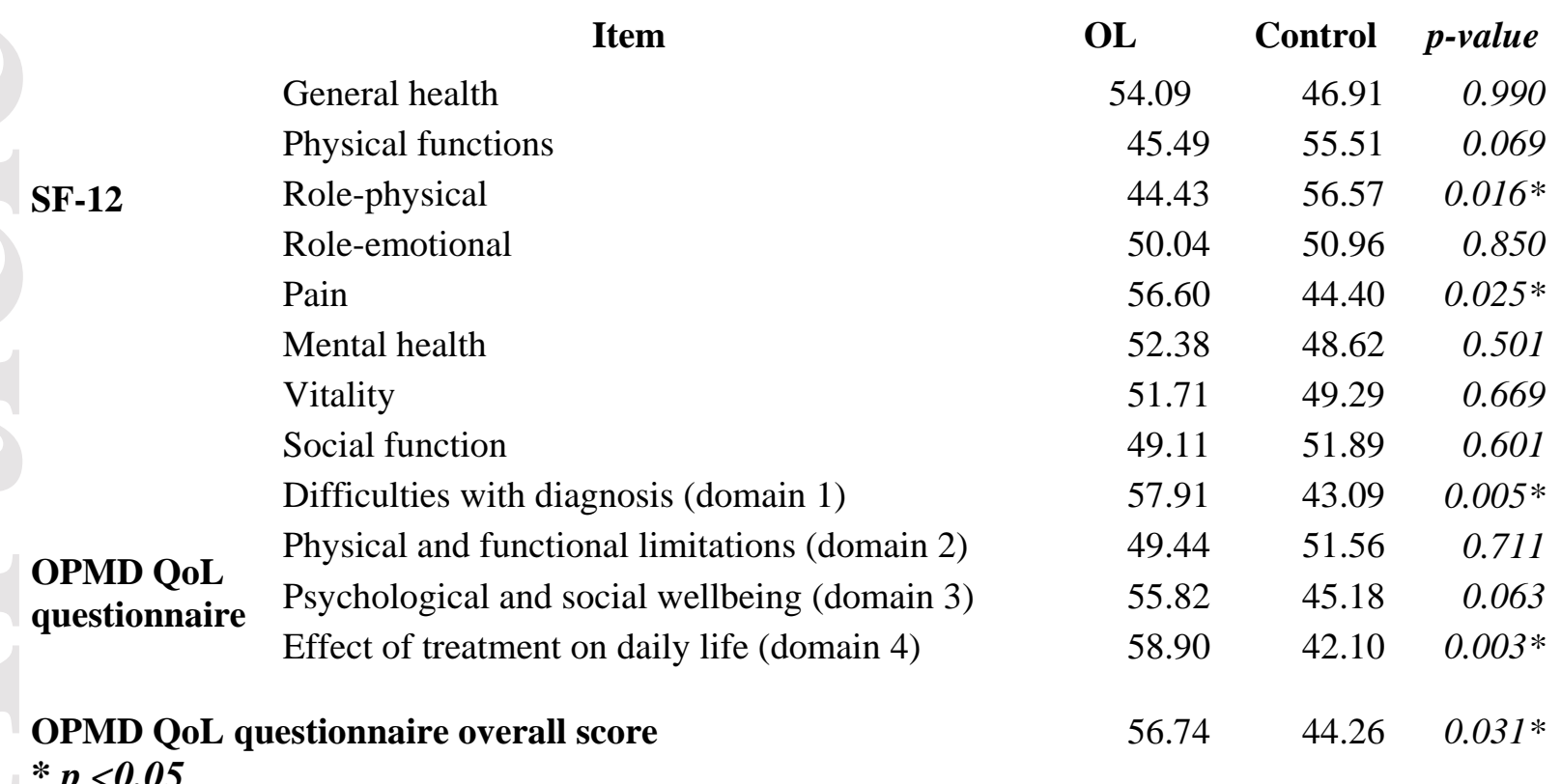

This article is protected by copyright. All rights reserved. 
TABLE 3: Impact of patient demographics and lesion characteristics on OPMD scores (Mean values of independent variables)

\begin{tabular}{|c|c|c|c|c|c|c|c|c|c|c|c|}
\hline D & & \multicolumn{2}{|c|}{$\begin{array}{l}\text { Difficulties with } \\
\text { diagnosis }\end{array}$} & \multicolumn{2}{|c|}{$\begin{array}{l}\text { Physical and functional } \\
\text { limitations }\end{array}$} & \multicolumn{2}{|c|}{$\begin{array}{c}\text { Psychological and social } \\
\text { wellbeing }\end{array}$} & \multicolumn{2}{|c|}{$\begin{array}{l}\text { Effect of treatment on daily } \\
\text { life }\end{array}$} & \multicolumn{2}{|c|}{$\begin{array}{l}\text { OPMD QoL overall } \\
\text { score }\end{array}$} \\
\hline \multirow{3}{*}{ Gender } & Male & 23.48 & \multirow[t]{2}{*}{$p=0.210$} & 20.68 & \multirow[t]{2}{*}{$p=0.004^{*}$} & 21.58 & \multirow[t]{2}{*}{$p=0.019 *$} & 26.45 & \multirow[t]{2}{*}{$p=0.565$} & 21.52 & \multirow[t]{2}{*}{$p=0.018^{*}$} \\
\hline & Female & 28.53 & & 32.73 & & 31.38 & & 24.08 & & 31.48 & \\
\hline & $<45$ years & 11.00 & \multirow{2}{*}{$p=0.063$} & 8.00 & \multirow[t]{2}{*}{$p=0.029 *$} & 22.17 & \multirow[t]{2}{*}{$p=0.680$} & 8.00 & \multirow[t]{2}{*}{$p=0.029 *$} & 14.33 & \multirow[t]{2}{*}{$p=0.170$} \\
\hline Age category & $>45$ years & 26.43 & & 26.62 & & 25.71 & & 26.62 & & 26.21 & \\
\hline & Yes & 24.06 & \multirow{2}{*}{$p=0.483$} & 18.98 & \multirow{2}{*}{$p=0.002 *$} & 20.90 & \multirow{2}{*}{$p=0.030^{*}$} & 24.54 & \multirow{2}{*}{$p=0.649$} & 18.90 & \multirow{2}{*}{$p=0.002 *$} \\
\hline Alcohol & No & 26.83 & & 31.52 & & 29.75 & & 26.38 & & 31.60 & \\
\hline & $<2 \mathrm{~cm}$ & 22.42 & \multirow[t]{2}{*}{$p=0.104$} & 22.27 & \multirow{2}{*}{$p=0.097$} & 22.13 & \multirow{2}{*}{$p=0.086$} & 24.00 & \multirow{2}{*}{$p=0.440$} & 21.40 & \multirow[t]{2}{*}{$p=0.038^{*}$} \\
\hline Lesion size & $>2 \mathrm{~cm}$ & 28.83 & & 29.00 & & 29.15 & & 27.13 & & 29.94 & \\
\hline Lesion & $\begin{array}{l}\text { Homogeneous } \\
\text { Non- }\end{array}$ & 21.57 & \multirow[t]{2}{*}{$p=0.065$} & 22.65 & $p=0.195$ & 21.72 & \multirow[t]{2}{*}{$p=0.087$} & 20.50 & $p=0.023^{*}$ & 20.83 & \multirow[t]{2}{*}{$p=0.036^{*}$} \\
\hline homogeneity & Hoтоgenеous & 28.85 & & 27.93 & & 28.72 & & 29.76 & & 29.48 & \\
\hline & Yes & 30.78 & \multirow{2}{*}{$p=0.013 *$} & 26.24 & \multirow{2}{*}{$p=0.736$} & 31.22 & \multirow{2}{*}{$p=0.010^{*}$} & 29.61 & \multirow{2}{*}{$p=0.061$} & 30.43 & \multirow{2}{*}{$p=0.027^{*}$} \\
\hline Dysplasia & No & 21.00 & & 24.87 & & 20.63 & & 22.00 & & 21.30 & \\
\hline
\end{tabular}

$* p<0.05$

This article is protected by copyright. All rights reserved. 
TABLE 4: Multivariate linear regression analysis with the generalized linear model controlling for patient characteristics (age and gender)

\begin{tabular}{llccc} 
& \multicolumn{1}{c}{ OPMD domain } & Significance & B coefficient & 95\% CI \\
\hline Smoking & Physical and functional limitations & $0.016^{*}$ & -3.863 & -6.870 to -0.856 \\
Alcohol & Physical and functional limitations & $0.001^{*}$ & -5.582 & -8.083 to -3.081 \\
& Psychological and social well-being & $0.034^{*}$ & -3.299 & -6.294 to -0.304 \\
& OMPD Grand total score & $0.002^{*}$ & -10.255 & -15.832 to -4.679 \\
Time since diagnosis & & & \\
(<6 months) & Physical and functional limitations & $0.002^{*}$ & -6.426 & -9.865 to -2.987 \\
Site (Floor of mouth) & Psychological and social well-being & $0.040^{*}$ & 9.668 & 0.502 to 18.833 \\
Treatment type & Psychological and social well-being & $0.036^{*}$ & -7.163 & -13.746 to -0.579
\end{tabular}

$$
* \mathrm{p}<0.05
$$


TABLE 5: Pearson's Chi-squared analyses between dichotomous variable pairs Association of variables P value Odds Ratio Relative Risk

\begin{tabular}{llrrr}
\hline Presence of medical condition & Use of medications & $<0.001^{*}$ & 41.000 & 4.556 \\
Older patients & Presence of medical condition & $0.001^{*}$ & 29.411 & 10.444 \\
Large lesions & Non-homogeneous lesion & $0.004^{*}$ & 5.667 & 2.615 \\
Asymptomatic lesions & Surveillance of lesion & $0.005^{*}$ & 13.846 & 2.835 \\
Presence of medical condition & Non-homogeneous lesion & $0.011^{*}$ & N/A & 2.500 \\
Non-smoker & Non-homogeneous lesion & $0.012^{*}$ & 4.800 & 2.118 \\
Older patients & Non-smoker & $0.013^{*}$ & N/A & 3.357 \\
Older patients & Use of medications & $0.014^{*}$ & 13.699 & 5.222 \\
Large lesions & Surveillance of lesion & $0.016^{*}$ & 4.433 & 2.585 \\
Presence of medical condition & Non-smoker & $0.022^{*}$ & 9.804 & 3.556 \\
Large lesions & Presence of medical condition & $0.024^{*}$ & N/A & 2.141 \\
Non-homogeneous lesions & Presence of dysplasia & $0.042^{*}$ & 3.322 & 1.708 \\
Drinker & Lesion smaller than 200mm & $0.046^{*}$ & 3.200 & 1.733
\end{tabular}

$* \mathrm{p}<0.05 . \mathrm{N} / \mathrm{A}=$ not applicable, odds ratio could not be calculated for this association due to value of 0 in one of the cross-tab categories.

This article is protected by copyright. All rights reserved. 